\title{
Rare cause for a non healing perianal fistula in an elderly male
} Chandrasinghe PC, MBBS ${ }^{1}$, Marasinhe NC, MBBS 1 , Abeyratne IGKP, MBBS ${ }^{1}$, Sangar TP, MBBS, MS ${ }^{2}$

1 Surgical Registrar, University Surgical Unit, Colombo North Teaching Hospital, Ragama. 2 Senior Registrar, University Surgical Unit, Colombo North Teaching Hospital, Ragama

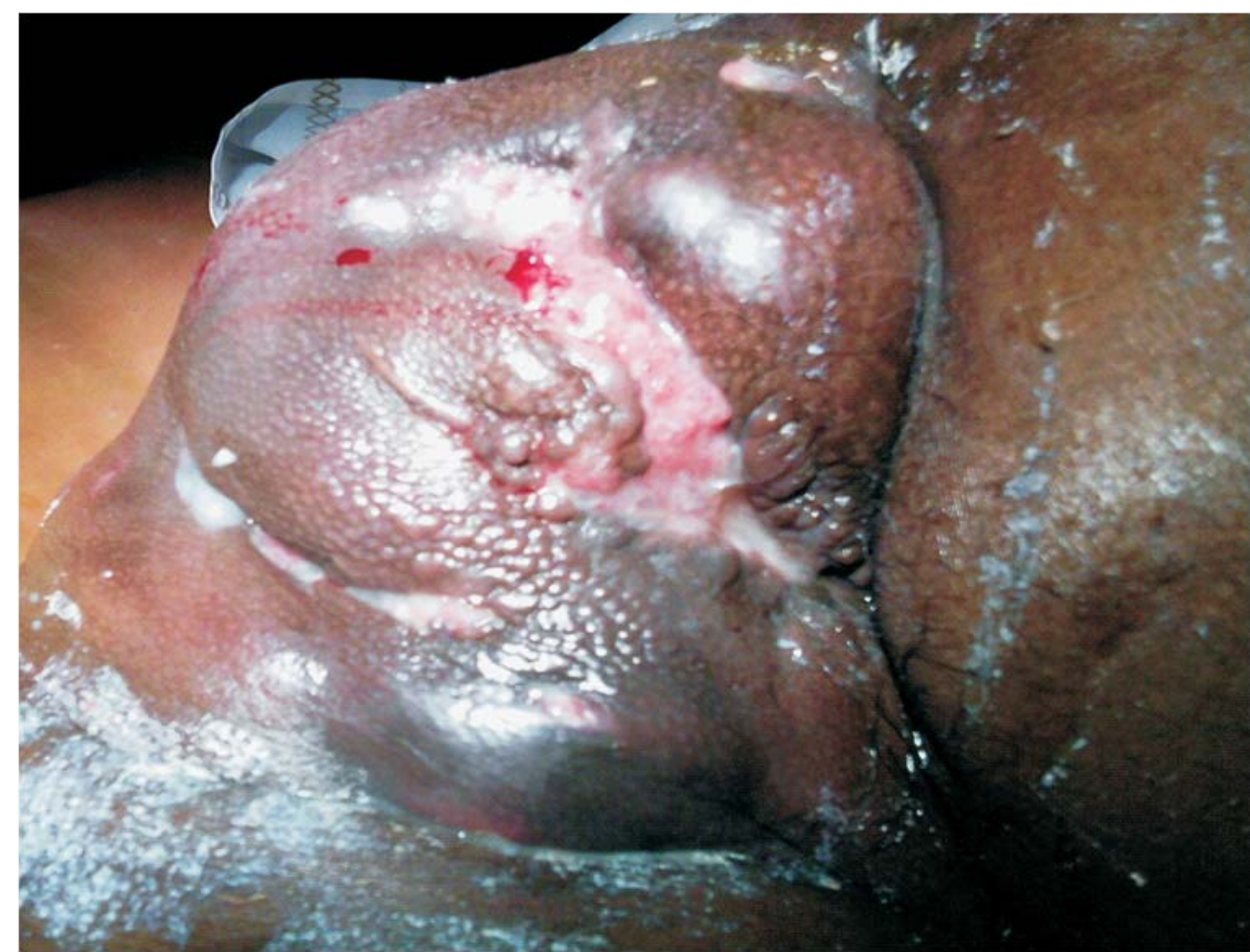

This was the appearance of the buttocks in a 65 year old male who was referred to us with a history of a non healing perianal fistula for two years. Copious amounts of mucous discharge from the wound was observed. The patient had had a peri-anal abscess drained, which later developed into a fistula-in-ano. He had undergone several unsuccessful attempts at fistulectomy which ended in him having a defunctioning colostomy. There was no preceding history of rectal bleeding or altered bowel habits. The area was hard and tender on palpation. There were no tumours palpable on digital rectal examination.

1. What should be the most appropriate course of action to reach a diagnosis?

2. What would be the likely diagnosis?

3. What are the available management strategies?

Correspondence: PC Chandrasinghe, Surgical Registrar, University

Surgical Unit, Colombo North Teaching Hospital, Ragama.

Email: pramodh@sltnet.lk

The Sri Lanka Journal of Surgery 2011; 29(2):108. 